\title{
Preparedness among Family Caregivers of Patients with Non- Communicable Diseases in Indonesia
}

\author{
Ike Wuri Winahyu Sari ${ }^{1}$, Novita Nirmalasari ${ }^{1}$ \\ ${ }^{I}$ Faculty of Health, Universitas Jenderal Achmad Yani Yogyakarta, Indonesia \\ Corresponding Author: Ike Wuri Winahyu Sari (ike.wuri@yahoo.com)
}

Received: 30 July 2020

Revised: 15 December 2020

Accepted: 21 December 2020

\begin{abstract}
Background: Family caregivers spend 24 hours a day looking after and assisting patients. However, they are not always adequately prepared for all the problems they face. There is a lack of evidence exploring caregivers' preparedness among family caregivers of patients with non-communicable diseases in Indonesia.

Purpose: This study aimed to identify caregivers' preparedness among family caregivers of patients with non-communicable diseases.

Methods: This cross-sectional study was conducted on 120 Indonesian family caregivers for patients with non-communicable diseases, who were selected using a purposive sampling technique. Data were collected using the Indonesian version of the Preparedness for Caregiving Scale (PCS) which had been validated before its use. The possible scores of this tool ranged from 0.00 to 4.00 . The higher the score, the more prepared the family caregivers were. Data were analyzed using one way ANOVA.

Results: Family caregivers reported the feeling of moderately prepared for caregiving. The score of family caregivers' preparedness for patients with diabetes, cancer, and chronic kidney disease were $2.97 \pm 0.42,2.83 \pm 0.40$, and $2.89 \pm 0.49$, respectively with a possible range from 0.00 to 4.00 . There were no differences in the preparedness among family caregivers of patients with non-communicable diseases $(p=0.387)$.

Conclusion: Caregivers' preparedness is an essential element of patient care. Nurses have to be proactive in assessing each family caregiver's preparedness to enhance the quality of life of both the family caregivers and the patients themselves so that they can be empowered as a source of nursing care.
\end{abstract}

Keywords: Caregiver preparedness; Indonesia; non-communicable disease; PCS

How to Cite: Sari, I. W. W., \& Nirmalasari, N. (2020). Preparedness among family caregivers of patients with non-communicable diseases in Indonesia. Nurse Media Journal of Nursing, 10(3), 340-349. doi:10.14710/nmjn.v10i3.31954

Permalink/DOI: https://doi.org/10.14710/nmjn.v10i3.31954

\section{BACKGROUND}

Chronic non-communicable diseases (NCDs) such as cancer, chronic kidney disease (CKD), and diabetes pose a significant ongoing public health problem. They are responsible for $75 \%$ of global mortality (Wang et al., 2016). Cancer and CKD have escalated by $0.4 \%$ and $1.8 \%$ respectively from 2013 to 2018 (Ministry of Health of 
Republic Indonesia, 2018). Also, diabetes is now globally in the top six of NCDs (International Diabetes Federation, 2017). The risk factors of the diseases need to be controlled to address patients' needs through self-management and family caregiver support with the supervision of the health care providers.

Cancer, diabetes, and CKD patients have both physical and emotional problems. Cancer patients have three main physical symptoms, namely, pain, fatigue, and difficulty sleeping. Furthermore, emotional problems that include depression, fear of the disease, and difficulty solving problems, seeking support, and avoiding problems are all associated with the disease (Effendy, Vissers, Tejawinata, Vernooij-Dassen, \& Engels, 2014; Werdani \& Silab, 2020). For diabetes patients, they have symptoms such as polyphagia, weight loss, fatigue, neuropathic complications, and prolonged infections (International Diabetes Federation, 2017). Patients with CKD also have related issues such as fatigue, nausea, vomiting, anemia, headaches, sleep changes, and psychological problems such as depression, anxiety, and social distress (El-Majzoub et al., 2019).

The family caregiver is an individual who looks after patients as an extension of the health care provider, and who provides care related to the functional status of family members suffering from an illness (Given, Given, \& Sherwood, 2012). They can be the spouse, parents, daughters or sons, or other relatives (Effendy et al., 2014). The studies conducted in East Java (Werdani \& Silab, 2020), and Yogyakarta and Central Java (Sari, Warsini, \& Effendy, 2018), Indonesia, showed that the patients have their nuclear family as their support system. Taking care of NCD patients has been transformed from curing the disease to offering comfort and a better quality of life. This situation is a challenge for family caregivers who take responsibility for caring for patients who suffer from NCDs (Rha, Park, Song, Lee, \& Lee, 2015; Wolff \& Jacobs, 2015). The challenge is that family caregivers spend 24 hours a day helping and assisting patients with their physical and psychological conditions, as well as financial and autonomous problems (Effendy et al., 2014; Machado, Dahdah, \& Kebbe, 2018). The study conducted by Sari et al. (2018) on 178 family caregivers of advanced cancer patients in Yogyakarta and Central Java showed that the burden was higher for family caregivers who spent more time each day looking after their sick family members.

The complicated problems among family caregivers are usually not balanced with their preparedness (Maheshwari \& Mahal, 2016). Their preparedness includes how ready the family caregivers see themselves for the tasks and roles demanded from them when looking after family members who suffer from illness, including the provision of physical care and emotional support, preparing support services at home, and compensating for the burden of responsibility (Gonzales, Polansky, Lippa, Gitlin, \& Zauszniewski, 2014; Petruzzo et al., 2017). It is also about dealing with the stress of the care process (Gonzales et al., 2014). Less-prepared caregivers feel anxious about the caring process, feel burdened, stressed, and have mood swings (Carter, Lyons, Stewart, Archbold, Scobee, 2010; Grant et al., 2013; Schumacher, Stewart, \& Archbold, 2007). Furthermore, they have poorer health than caregivers who are better prepared (Ahn, Hochhalter, Moudouni, Smith, \& Ory, 2012). In contrast, well-prepared caregivers with appropriate skills and knowledge feel happy about the care they provide; they have better hope (Henriksson, 
Andershed, Benzein, \& Arestedt, 2012) and well-being, both physically and emotionally (Shyu et al., 2010).

It is essential to investigate the caregivers' preparedness as the preparedness has been shown to predict caregiving rewards and improve family caregivers' mental health as well as patients' quality of life. The preparedness of family caregivers has been confirmed in the previous studies from New York (Otto et al., 2020), Ohio (Mazanec, Reichlin, Gittleman, \& Daly, 2018), China (Liu et al., 2020), India (Maheswari \& Mahal, 2016), and Italy (Petruzzo et al., 2018, Vellone et al., 2020). However, they only focused on preparedness for a specific disease such as stroke, congestive heart failure, and cancer. The family caregivers for each disease play a different role in caregiving situations because they have different complex problems and needs. To the authors' knowledge, there was no study comparing the preparedness among family caregivers of cancer, CKD, and diabetes in Indonesia, especially in Yogyakarta. For these reasons, there is a need for more attention to caregivers' preparedness for patients with cancer, CKD, and diabetes that has not yet been compared in the previous studies.

\section{PURPOSE}

This study aimed to identify and assess the differences in the caregivers' preparedness among family caregivers for cancer, diabetes, and CKD patients.

\section{METHODS}

\section{Research design and samples}

This study was a descriptive-analytic study using a cross-sectional approach. Data were collected from June to July 2020 from 120 family caregivers of NCD patients selected using a purposive sampling technique. There were 40 family caregivers of cancer patients in the Oncological Clinic of one general hospital in Bantul, Yogyakarta; 40 family caregivers of CKD patients in hemodialysis units of a general hospital in Bantul, Yogyakarta; and 40 family caregivers of diabetes patients in Candibinangun village, which were in the area of a public health centre in Sleman, Yogyakarta. The eligibility criteria of the family caregivers were: (1) a family member that was looking after a patient with NCD and confirmed as the primary caregiver by the patient (they could be the spouse, parent, adult child, or relative); (2) being a family caregiver for at least two months; (3) living with the patient or delivering care for at least three hours per day; (4) adults (18 years or older); and (5) willing to consent to participate in the study.

\section{Instruments}

This study used two questionnaires. The first one was for the demographics of the respondents, and another one was the Preparedness for Caregiving Scale (PCS). The demographic questionnaire included the respondents' age, religion, gender, marital status, education level, monthly income, relationship with the patient, functional status, length of care, the current treatment for the patients, and health education experience about the patients' illnesses. The original version of the PCS (Archbold, Stewart, Greenlick, \& Harvath, 1990), was translated into Indonesian, and re-named the Indonesian version of PCS (I-PCS). The permission had already been granted from the developers, Archbold et al. (1990), to translate the original version into the Indonesian language by providing a proper citation. All the items in the I-PCS were confirmed to be valid and reliable, with 
Pearson- $r$ values higher than 0.320 , and the Cronbach's alpha coefficient value was 0.933 . I-PCS consisted of eight questions with five answer choices using a Likert scale ranging from 0 (not at all prepared) to 4 (very well prepared) and one open question about the specific preparedness desirable in the caregiving process. The possible score ranged from 0.00 to 4.00 . The higher the score, the more prepared the family caregivers were.

\section{Data collection}

The family caregivers for cancer and CKD who met eligibility criteria were identified through the ward manager based on the medical record. Meanwhile, the family caregivers for diabetes were identified through data from the public health centre by cadres in that area. They were fully informed about the study's aim and signed the informed consent after they were identified as potential respondents. Then, the family caregivers completed the instruments, including the socio-demographic and caregiver preparedness questionnaires. The completed forms were corrected and clarified again to the respondents before they were processed and analyzed. Four research assistants administered the data collection.

\section{Data analysis}

The Statistical Package for Social Sciences (SPSS) version 21 software package (IBM SPSS, Chicago, IL, USA) was used for data entry and analysis. Descriptive statistics were used to summarize the demographic characteristics and caregivers' preparedness. The Shapiro Wilk normality test was used to describe the normality of the numerical data. The result showed that caregivers' preparedness in each group had a normal distribution $(p>0.05)$, so a one-way ANOVA test was used to assess the differences on caregivers' preparedness for cancer, diabetes, and CKD patients. A p-value of $<0.05$ was considered to be significant.

\section{Ethical issues}

The Health Research Ethics Committee, Faculty of Health, Universitas Jenderal Achmad Yani Yogyakarta, approved all the materials and protocols used in this study (Number: SKep/05/KEPK/II/2020). Family caregivers were fully informed about the aims of the study. They signed an informed consent form and were informed that they could withdraw from the study at any time. They were also assured that all collected data would be kept confidential.

\section{RESULTS}

\section{Demographic characteristics of the respondents}

The respondents' characteristics are shown in Table 1 . There were 40 consenting family caregivers for each disease included in the final analysis. The mean age of the family caregivers for diabetes, cancer, and CKD patients was $48.26 \pm 15.13,39.54 \pm 12.30$, and $47.95 \pm 12.17$ years old, respectively. The majority of family caregivers were female for diabetes and male for cancer and CKD, Moslem, and married. Most family caregivers for diabetes and CKD were spouses, and for cancer, they were parents. Most of them had a senior high school education, and a low-income level. Only $85.0 \%$ and $80 \%$ had ever received health education about diabetes and CKD, respectively, while $82.5 \%$ had no health education for cancer. The majority of the treatment experienced by diabetes patients' caregivers was in seeking medical treatment $(80.0 \%)$, while it was 
chemotherapy for cancer caregivers (40.0\%), and hemodialysis for CKD caregivers (100\%). They all had good health and had been taking care of the patients for approximately a minimum of two months up to two years.

Table 1. Demographic characteristics of family caregivers $(n=120)$

\begin{tabular}{|c|c|c|c|c|c|c|}
\hline \multirow{2}{*}{ Characteristics } & \multicolumn{2}{|c|}{ Diabetes $(n=40)$} & \multicolumn{2}{|c|}{ Cancer $(n=40)$} & \multicolumn{2}{|c|}{ CKD $(n=40)$} \\
\hline & $f$ & $\%$ & $f$ & $\%$ & $f$ & $\%$ \\
\hline \multicolumn{7}{|l|}{ Age (years) } \\
\hline$M e a n \pm S D$ & \multicolumn{2}{|c|}{$48.26 \pm 15.13$} & \multicolumn{2}{|c|}{$39.54 \pm 12.30$} & \multicolumn{2}{|c|}{$47.95 \pm 12.17$} \\
\hline \multicolumn{7}{|l|}{ Gender } \\
\hline Female & 27 & 67.5 & 18 & 45 & 14 & 35 \\
\hline Male & 13 & 32.5 & 22 & 55 & 26 & 65 \\
\hline \multicolumn{7}{|l|}{ Religion } \\
\hline Moslem & 36 & 90 & 40 & 100 & 39 & 97.5 \\
\hline Catholic & 4 & 10 & - & - & 1 & 2.5 \\
\hline \multicolumn{7}{|l|}{ Marital status } \\
\hline Single & 4 & 10 & 6 & 15 & 3 & 7.5 \\
\hline Widow/widower & 1 & 2.5 & - & - & - & - \\
\hline Married & 35 & 87.5 & 34 & 85 & 37 & 92.5 \\
\hline \multicolumn{7}{|l|}{ Relationship with patient } \\
\hline Spouse & 22 & 55 & 10 & 25 & 29 & 72.5 \\
\hline Parent & 14 & 35 & 24 & 60 & 9 & 22.5 \\
\hline Child & 2 & 5 & - & - & 1 & 2.5 \\
\hline $\begin{array}{l}\text { Relatives (brother, } \\
\text { grandmother) }\end{array}$ & 2 & 5 & 6 & 15 & 1 & 2.5 \\
\hline \multicolumn{7}{|l|}{ Education level } \\
\hline Illiterate & - & - & 1 & 2.5 & - & - \\
\hline Elementary school & 4 & 10 & 3 & 7.5 & 5 & 12.5 \\
\hline Junior high school & 5 & 12.5 & 5 & 12.5 & 12 & 30 \\
\hline Senior high school & 24 & 60 & 23 & 57.5 & 19 & 47.5 \\
\hline College & 7 & 17.5 & 8 & 20 & 4 & 10 \\
\hline \multicolumn{7}{|l|}{ Family income ${ }^{a}$} \\
\hline$<$ Minimum income level & 35 & 87.5 & 25 & 62.5 & 32 & 80 \\
\hline$\geq$ Minimum income level & 5 & 12.5 & 15 & 37.5 & 8 & 20 \\
\hline \multicolumn{7}{|l|}{ Health education experience } \\
\hline No & 6 & 15 & 33 & 82.5 & 8 & 20 \\
\hline Yes & 34 & 85 & 7 & 17.5 & 32 & 80 \\
\hline \multicolumn{7}{|l|}{ Health status } \\
\hline Good & 40 & 100 & 40 & 100 & 40 & 100 \\
\hline $\begin{array}{l}\text { Have symptoms of a } \\
\text { disease }\end{array}$ & - & - & - & - & - & - \\
\hline \multicolumn{7}{|l|}{ Patient's treatment } \\
\hline Chemotherapy & - & - & 16 & 40 & - & - \\
\hline Surgery & - & - & - & - & - & - \\
\hline Seek medical treatment & 32 & 80 & - & - & - & - \\
\hline Hemodialysis & 2 & 5 & - & - & 40 & 100 \\
\hline $\begin{array}{l}\text { Oral medication combined } \\
\text { with transfusion }\end{array}$ & - & - & 4 & 10 & - & - \\
\hline Chemotherapy and surgery & - & - & 13 & 32.5 & - & - \\
\hline
\end{tabular}


Table 1. (Continued)

\begin{tabular}{|c|c|c|c|c|c|c|}
\hline \multirow{2}{*}{ Characteristics } & \multicolumn{2}{|c|}{ Diabetes $(n=40)$} & \multicolumn{2}{|c|}{ Cancer $(n=40)$} & \multicolumn{2}{|c|}{ CKD $(n=40)$} \\
\hline & $f$ & $\%$ & $f$ & $\%$ & $f$ & $\%$ \\
\hline $\begin{array}{l}\text { Chemotherapy, surgery, } \\
\text { and radiotherapy }\end{array}$ & - & - & 7 & 17.5 & - & - \\
\hline $\begin{array}{l}\text { Others (diet, no current } \\
\text { treatment) }\end{array}$ & 6 & 15 & - & - & - & - \\
\hline Stage of cancer & $\mathrm{N} / \mathrm{A}$ & & & & N/A & \\
\hline I & & & 3 & 7.5 & & \\
\hline II & & & 4 & 10 & & \\
\hline III & & & 15 & 37.5 & & \\
\hline IV & & & 8 & 20 & & \\
\hline Unknown & & & 10 & 25 & & \\
\hline \multicolumn{7}{|l|}{ Length of care (months) } \\
\hline Median (Min-Max) & \multicolumn{2}{|c|}{$30(4-240)$} & \multicolumn{2}{|c|}{$10(2-180)$} & \multicolumn{2}{|c|}{$18(3-108)$} \\
\hline
\end{tabular}

${ }^{a}$ the minimum income level in Yogyakarta, Indonesia: 1,790,500 IDR; SD=Standard Deviation; Min=Minimum; Max=Maximum; N/A=No available data

\section{The caregivers' preparedness}

The preparedness of family caregivers for NCD patients is summarized in Table 2. The caregivers' preparedness among family caregivers of NCD patients was in the range from 2.83 to $2.97( \pm 0.40$ to \pm 0.49 ). The lowest caregivers' preparedness was for cancer caregivers $(2.83 \pm 0.40)$, and the highest preparedness was for the diabetes caregivers $(2.97 \pm 0.42)$.

Table 2. The caregiver preparedness among family caregiver of NCD patients $(n=120)$

\begin{tabular}{|c|c|c|c|c|}
\hline \multirow[b]{2}{*}{ Caregiver preparedness } & \multirow[b]{2}{*}{ Possible range } & Diabetes & Cancer & CKD \\
\hline & & $M e a n+S D$ & $M e a n+S D$ & $M e a n+S D$ \\
\hline The I-PCS score & $0.00-4.00$ & $2.97 \pm 0.42$ & $2.83 \pm 0.40$ & $2.89 \pm 0.49$ \\
\hline
\end{tabular}

The specific desirable preparedness in the caregiving process is shown in Figure 1. From this result, it can be concluded that financial preparedness is the principal preparedness that is desirable by the family caregivers $(63.0 \%)$.

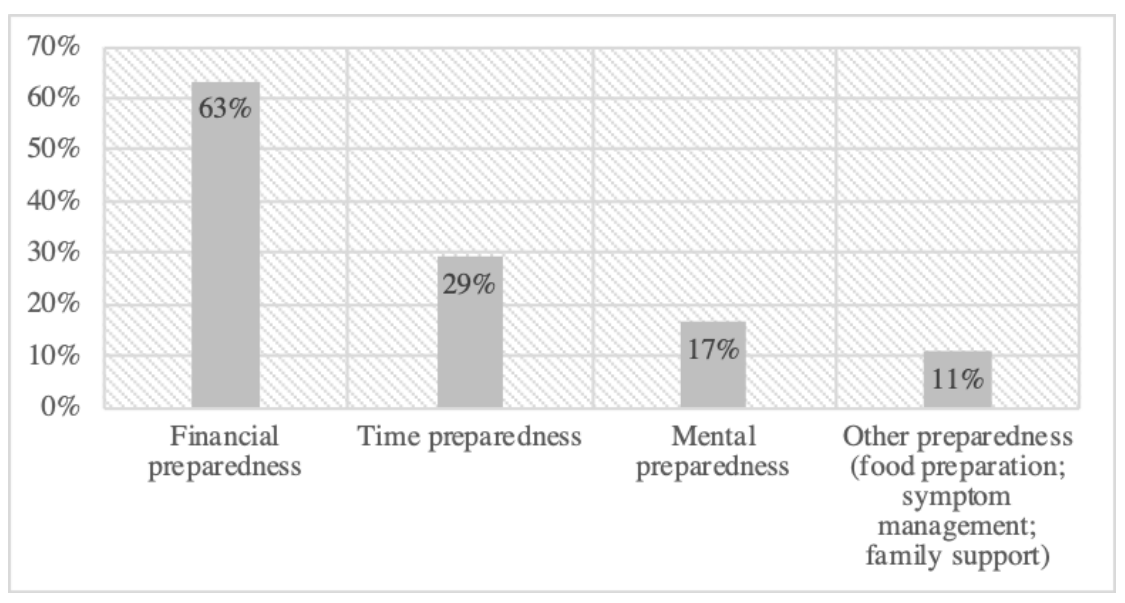

Figure 1. The desirable preparedness in caregiving process $(n=120)$ 


\section{The comparison of caregivers' preparedness of NCD patients}

The comparison of caregivers' preparedness among family caregivers for diabetes, cancer, and CKD is shown in Table 3. There were no differences on the caregivers' preparedness among family caregivers for diabetes, cancer, and CKD $(p=0.387)$.

Table 3. The comparison of caregivers' preparedness among diabetes, cancer, and CKD patients $(n=120)$

\begin{tabular}{llllc}
\hline Caregiver preparedness & NCD & $n$ & Mean $\pm S D$ & $p$ \\
\hline The I-PCS score & Diabetes & 40 & $2.97 \pm 0.42$ & $0.387^{\text {a }}$ \\
& Cancer & 40 & $2.83 \pm 0.40$ & \\
& CKD & 40 & $2.89 \pm 0.49$ & \\
\hline
\end{tabular}

a One-way ANOVA significant with $p<0.05$; NCD=Non-communicable disease; I-PCS=The Indonesian version of the Preparedness for Caregiving Scale

\section{DISCUSSION}

This study is a limited study outlining how well-prepared family caregivers are to look after their family members suffering from chronic illnesses in Indonesia. On average, family caregivers reported feeling moderately prepared for caregiving. A study in New York on 84 family caregivers for cancer patients showed the same result. The family caregivers reported a moderate level of preparedness $(M=21.33$, possible range $=0$ to 32$)$ (Otto et al., 2020). The previous study in Ohio family caregivers showed a lower range of preparedness for the admission phase than this current study (2.65 \pm 0.78$)$. However, during the post-discharge phase, the score escalated and had the same range as this current study (2.97 \pm 0.72 ) (Mazanec et al., 2018).

In the Asian context and especially in the Indonesian culture, there is a large family structure called an extended family (Subandi, 2011) with a strong bond between each other (Subandi, 2011; Yoon, Kim, Jung, Kim, \& Kim, 2014). Although NCDs require a caregiving process, it is still considered to be a "normal condition" for people in Indonesia. Looking after sick family members, such as by providing personal care, daily need, and health management (Kaye, Harrington, \& LaPlante, 2010) is, in Indonesian culture, accepted as a duty that should not be questioned (Funk, Chappell, \& Liu, 2011; Kristanti et al., 2017). To be a caregiver for their loved ones suffering from illness is natural. This condition makes the family caregivers feel more prepared to look after their family members, so they become more confident in doing this (Vellone et al., 2020).

This study demonstrates a contrasting result with Maheswari \& Mahal (2016) for 226 family caregivers of cancer patients in India. The mean of their preparedness was at a low level (13.56 \pm 2.8$)$ with a possible range from 9.00 to 22.00. A lack of caregivers' preparedness was also an issue for Italian family caregivers who cared for heart failure patients. Their PCS score was 2.13 \pm 0.77 (Petruzzo et al., 2018) and 2.11 \pm 0.76 (Vellone et al., 2020) with a possible range of 0.00 to 4.00 . Contrary to this current study, a study of Chinese family caregivers for stroke patients demonstrated a considerably low score for their preparedness $(M=4.42$ of 32.00$)$, indicating that the family caregivers were not well prepared (Liu et al., 2020). The low level of preparedness occurred due to family caregivers' inadequate training for their caregiving skills and education (Maheswari \& Mahal, 2016). The significant factors that affected the low preparedness were low 
educational background and caregiving experience. The low educational level could affect the family caregivers' ability to communicate effectively with the health care providers. The higher the degree of education, the greater the preparedness since they had a more excellent opportunity to improve awareness and expertise and gain more accurate caregiving information (Liu et al., 2020).

Surprisingly, there were no differences on caregivers' preparedness for diabetes, cancer, and CKD patients in this current study. It means that all the family caregivers who look after family members suffering from chronic illnesses have the same moderate preparedness. The moderate level of preparedness means that the family caregivers feel prepared but, on the other hand, also need help in certain situations. This may happen because all chronic illnesses, including cancer, CKD, and diabetes, have the same problems that must be faced by a family caregiver. The problems include physical and psychological aspects (Effendy et al., 2014; Machado et al., 2018). The family caregivers must prepare for caring process, such as preparedness to provide physical care, emotional support, support services at home, and compensation for the burden of care resulting from the caring process (Petruzzo et al., 2017).

Interestingly, the cancer family caregivers had the lowest preparedness compared to the others in this study. Uncertainty about cancer is considered a significant source of psychological distress (Guan, Santacroce, Chen, \& Song, 2020). Besides this, the degree of severity of the disease also influences the caregivers' preparedness (Liu et al., 2020; White, Barrientos, \& Dunn, 2014). The family caregivers felt severe pressure, burdened, and anxiety about their patients' disease. They could not predict whether the healthcare team would provide help, which would have a significant impact on the caregivers' preparedness (White et al., 2014).

The additional question (item number 9 of the I-PCS) showed that the family caregivers want to be better prepared for the financial aspects of illness. The family caregivers in this study faced financial problems because they had low-income levels. Although they received some funding from National Insurance programmes (i.e., BPJS or KIS), there were still other expenses that the insurance could or would not cover. These expenses, such as for specific drugs, specific diagnostic procedures, accommodation and other needs, such as food, occur during the process of seeking treatment (Kristanti et al., 2017).

This study has limitations such as having no data about what kind of caring the family caregivers give to their loved ones. The kind of caring would be valued data for comparing the caregivers' preparedness on each disease. The data in this study were collected at one-time period, so any dynamic changes could not be evaluated. However, this study is relatively heterogeneous because it captures three problems and has a low level of missing data indicating the accurate preparedness score.

\section{CONCLUSION}

In conclusion, caregiver preparedness is an essential element of care. Caregiver's preparedness in this study was in moderate level. The healthcare team needs to screen the preparedness of family caregivers because this is a critical step as they are an excellent source for optimized quality of care. As family caregivers also play an essential role in 
palliative care, family members need to include in the medical record to be part of advance care planning. The I-PCS is highly recommended for use in the hospital or public care services settings. It is a valid and reliable scale that could facilitate nurses to measure caregivers' preparedness. This assessment's response can be used to plan the interventions to enhance the preparation of family caregivers with a family-centered care approach. The interventions can be encompassing routine assessment for the family caregivers, promoting the knowledge with education and basic training skills of care, and always making excellent communication. Further research is needed to investigate the interventions to improve family caregivers' preparedness. The study that highlights the caregiving role and patients' quality of life is also needed to investigate whether the caregivers' preparedness affects them or not.

\section{ACKNOWLEDGEMENT}

The authors would like to thank the family caregivers who contributed to this work and the Ministry of Research and Technology of Indonesia for funding the project.

\section{CONFLICT OF INTEREST}

\section{None.}

\section{REFERENCES}

Ahn, S., Hochhalter, A.K., Moudouni, D.K., Smith, M.L., \& Ory, M.G. (2012). Selfreported physical and mental health of older adults: The roles of caregiving and resources. Maturitas, 71, 62-69. doi:10.1016/j.maturitas.2011.10.011

Archbold, P.G., Stewart, B.J., Greenlick, M.R., \& Harvath, T. (1990). Mutuality and preparedness as predictors of caregiver role strain. Research in Nursing \& Health, 13, 375-384. doi:10.1002/nur.4770130605

Carter, J.H., Lyons, K.S., Stewart, B.J., Archbold, P.G., \& Scobee, R. (2010). Does age make a difference in caregiver strain? Comparison of young versus older caregivers in early-stage Parkinson's disease. Movement Disorders, 25, 724-730. doi:10.1002/mds.22888.

Effendy, C., Vissers, K., Tejawinata, S., Vernooij-Dassen, M., Engels, Y. (2014). Dealing with symptoms and issues of hospitalized patients with cancer in Indonesia: The role of families, nurses, and physicians. Pain Practice, 15(5), 441-6. doi:10.1111/papr.12203.

El-Majzoub, S., Mucsi, I., Li, M., Moussaoui, G., Lipman, M.L., Looper, K.J., ..., \& Rej, S. (2019). Psychosocial distress and health service utilization in patients undergoing hemodialysis: A prospective study. Psychosomatics, 60(4), 385-392. doi:10.1016/j.psym.2018.10.001

Funk, L. M., Chappell, N. L. \& Liu, G. (2011). Associations between filial responsibility and caregiver well-being: are there differences by cultural group? Research on Aging, 35(1), 78-95. doi:10.1177/0164027511422450

Given, B.A., Given, C.W., \& Sherwood, P. (2012). The challenge of quality cancer care for family caregivers. Seminars in Oncology Nursing, 28 (4), 205-212. doi:10.1016/j.soncn.2012.09.002

Gonzales, E. W., Polansky, M., Lippa, C. F., Gitlin, L. N., \& Zauszniewski, J. A. (2014). Enhancing resourcefulness to improve outcomes in family caregivers and 
persons with alzheimer's disease: A pilot randomized trial. International Journal of Alzheimer's Disease, 1-10. doi:10.1155/2014/323478

Grant, M., Sun, V., Fujinami, R., Sidhu, R., Otis-Green, S., Juarez, G., ..., \& Ferrell, B. (2012). Family caregiver burden, skills preparedness, and quality of life in nonsmall cell lung cancer. Oncology Nursing Forum, 40, 337-346. doi:10.1188/13.ONF.337-346

Guan, T., Santacroce, S. J., Chen, D., \& Song, L. (2020). Illness uncertainty, coping, and quality of life among patients with prostate cancer. Psycho-Oncology, 29(6), 10191025. doi:10.1002/pon.5372

Henriksson, A., Andershed, B., Benzein, E., \& Arestedt, K. (2012). Adaptation and psychometric evaluation of the preparedness for caregiving scale, caregiver competence scale and rewards of caregiving scale in a sample of Swedish family members of patients with life-threatening illness. Palliative Medicine, 26, 930-938. doi:10.1177/0269216311419987

International Diabetes Federation (IDF). (2017). IDF Clinical practice recommendation for managing type 2 diabetes in primary care. ISBN: 978-2-930229-85-0. Retrieved from www.idf.org/managing-type2-diabetes.

Kaye, H. S., Harrington, C., \& LaPlante, M. P. (2010). Long-term care: Who gets it, who provides it, who pays, and how much?. Health Affairs, 29(1), 11-21. doi:10.1377/hlthaff.2009.0535

Kristanti, M. S., Engels, Y., Effendy, C., Astuti, Utarini, A., \& Vernooij-Dassen, M. (2017). Comparison of the lived experiences of family caregivers of patients with dementia and of patients with cancer in Indonesia. International Psychogeriatrics, 30(6), 903-914. doi:10.1017/s1041610217001508

Liu, J., Liu, Q., Huang, Y., Wang, W., He, G., \& Zeng, Y. (2020). The effects of personal characteristics, disease uncertainty and knowledge on family caregivers' preparedness of stroke survivors: A cross-sectional study. Nursing \& Health Sciences, 22(4), 892-902. doi:10.1111/nhs.12743

Machado, B.M., Dahdah, D.F., \& Kebbe, L.M. (2018). Caregivers of family members with chronic diseases: coping strategies used in everyday life. Cadernos Brasileiros de Terapia Ocupacional, 26(2), 299-313. doi:10.4322/2526-8910.ctoao1188

Maheshwari, P.S. \& Mahal, R.K. (2016). Relationship of preparedness and burden among family caregivers of cancer patients in India. Journal of Health, Medicine, and Nursing, 22, 35-44.

Mazanec, S., Reichlin, D., Gittleman, H., \& Daly, B. (2018). Perceived needs, preparedness, and emotional distress of male caregivers of postsurgical women with gynecologic cancer. Oncology Nursing Forum, 45(2), 197-205. doi:10.1188/18.onf.197-205

Ministry of Health of Republic Indonesia. (2018). Hasil utama Riset Kesehatan Dasar (RISKESDAS) 2018 [Main results of Basic Health Research (RISKESDAS) 2018]. Jakarta: Kementerian Kesehatan Badan Penelitian dan Pengembangan Kesehatan. Retrieved from https://www.kemkes.go.id/resources/download/info-terkini/hasilriskesdas-2018.pdf.

Otto, A. K., Ketcher, D., Heyman, R. E., Vadaparampil, S. T., Ellington, L., \& Reblin, M. (2020). Communication between advanced cancer patients and their family caregivers: Relationship with caregiver burden and preparedness for caregiving. Health Communication, 1-8. doi:10.1080/10410236.2020.1712039 
Petruzzo, A., Biagioli, V., Durante, A., Emberti Gialloreti, L., D’Agostino, F., Alvaro, R., \& Vellone, E. (2018). Influence of preparedness on anxiety, depression, and quality of life in caregivers of heart failure patients: Testing a model of path analysis. Patient Education and Counseling, 102(5), 1021-1028. doi:10.1016/j.pec.2018.12.027

Petruzzo, A., Paturzo, M., Buck, H.G., Barbaranelli, C., A’Agostino, F., Ausili, D., ...., \& Vellone, E. (2017). Psychometric evaluation of the caregiver preparedness scale in caregivers of adults with heart failure. Research in Nursing \& Health, 40(5), 470478. doi:10.1002/nur.21811

Rha, S.Y., Park, Y., Song, S.K., Lee, C.E., \& Lee, J. (2015). Caregiving burden and the quality of life of family caregivers of cancer patients: the relationship and correlates. European Journal of Oncology Nursing, 19, 376-382. doi: 10.1016/j.ejon.2015.01.004

Sari, I.W.W., Warsini, S., \& Effendy, C. (2018). Burden among family caregivers of advanced-cancer patients in Indonesia. Belitung Nursing Journal, 4(3), 295-303. doi:10.33546/bnj.479

Schumacher, K.L., Stewart, B.J., \& Archbold, P.G. (2007). Mutuality and preparedness moderate the effects of caregiving demand on cancer family caregiver outcomes. Nursing Research, 56, 425-433. doi:10.1097/01.NNR.0000299852.75300.03

Shyu, Y.I., Yang, C.T., Huang, C.C., Kuo, H.C., Chen, S.T., \& Hsu, W.C. (2010). Influences of mutuality, preparedness, and balance on caregivers of patients with dementia. The Journal of Nursing Research, 18 (3), 155-163. doi:10.1097/JNR.0b013e3181ed5845

Subandi, M. (2011). Family expressed emotion in a Javanese cultural context. Culture, Medicine, and Psychiatry, 35(3), 331-346. doi:10.1007/s11013-011-9220-4

Vellone, E., Biagioli, V., Durante, A., Buck, H. G., Iovino, P., Tomietto, M., ..., \& Petruzzo, A. (2020). The influence of caregiver preparedness on caregiver contributions to self-care in heart failure and the mediating role of caregiver confidence. The Journal of Cardiovascular Nursing, 35(3), 243-252. doi: $10.1097 /$ jen.0000000000000632

Wang, H., Naghavi, M., Allen, C., Barber, R.M., Bhutta, Z., Carter, A., ..., \& Murray, C.J.L. (2016). Global, regional, and national life expectancy, all-cause mortality, and cause-specific mortality for 249 causes of death, 1980-2015: a systematic analysis for the Global Burden of Disease Study 2015. The Lancet, 388 (10053), 1459-1544. doi: 10.1016/S0140-6736(16)31012-1

Werdani, Y.D.W., \& Silab, P.A.A. (2020). Self-efficay affects cancer patients in solving problems, seeking support and avoiding problems as coping mechanisms. Nurse Media Journal of Nursing, 10(2), 146-157. doi:10.14710/nmjn.v10i2.26803

White, C. L., Barrientos, R., \& Dunn, K. (2014). Dimensions of uncertainty after stroke. Journal of Neuroscience Nursing, 46(4), 233-240. doi:10.1097/jnn.0000000000000066

Wolff, J. L., \& Jacobs, B. J. (2015). Chronic illness trends and the challenges to family caregivers. Family Caregiving in the New Normal, 79-103. doi:10.1016/b978-012-417046-9.00007-6

Yoon, S-J., Kim, J-S., Jung, J-G., Kim, S-S., \& Kim, S. (2014). Modifiable factors associated with caregiver burden among family caregivers of terminally ill Korean cancer patients. Support Care Cancer, 22, 1243-1250. doi:10.1007/s00520-0132077-z 